\title{
Juvenile amyotrophic lateral sclerosis
}

INSERM

\section{Source}

INSERM. (1999). Orphanet: an online rare disease and orphan drug data base. Juvenile amyotrophic lateral sclerosis. ORPHA:300605

Juvenile amyotrophic lateral sclerosis (JALS) is a very rare severe motor neuron disease characterized by progressive upper and lower motor neuron degeneration causing facial spasticity, dysarthria, and gait disorders with onset before 25 years of age. 